\title{
Wyniki XI edycji konkursu fotograficznego „Przeglądu Socjologii Jakościowej”
}

DOI: https://doi.org/10.18778/1733-8069.17.2.08

\section{Drodzy Czytelnicy,}

miniony rok obfitował $\mathrm{w}$ wiele niecodziennych wydarzeń, takich jak: pandemia i jej wpływ na naszą codzienność, Strajk Kobiet, protesty środowisk LGBT+. Wszystko to znalazło swój wyraz w nadesłanych pracach.

Tym razem nie zdecydowaliśmy się na przyznanie pierwszej nagrody. Wyróżniliśmy natomiast dwa eseje. Pierwszy, autorstwa Pana Piotra Szenajcha, nosi tytuł „Nigdy nie będziesz szła sama” i pokazuje, jak gorącą atmosferę i jak wyjątkową formę przybierają dzisiejsze protesty. Może to być na przykład happening, w którym ważkie społecznie i politycznie postulaty głoszone są w trakcie kolorowej, spontanicz- nej i oczyszczającej zabawy. Drugi, wykonany przez Panią Elżbietę Prucnal-Tumasz, ma w tytule pytanie, „Czy można przewidzieć przyszłość?” i - jak się wydaje - nie jest to pytanie czysto retoryczne. Okazuje się, że plakaty sfotografowane w 2012 roku niezwykle trafnie oddają klimat roku 2020. Biały knebel łudząco przypomina maseczkę, która chroni przed wirusem, ale jest też symbolem społecznej izolacji.

Zapraszamy do zapoznania się z wyróżnionymi pracami.

W imieniu Jury Waldemar Dymarczyk 


\section{Nigdy nie będziesz szła sama - fotoreportaż}

Manifestacja pod hasłem „Nigdy nie będziesz szła sama” była protestem przeciwko zatrzymaniu przez policję 48 osób na Krakowskim Przedmieściu w Warszawie 7 sierpnia 2020 roku.

Wśród zatrzymanych były osoby, które blokowały aresztowanie działaczki inicjatywy Stop Bzdurom, Małgorzaty „Margot” Szutowicz, ale też przypadkowi przechodnie.

Działaczka została oskarżona o zniszczenie plandeki furgonetki z napisami zrównującymi homoseksualizm z pedofilią oraz użycie przemocy wobec kierowcy samochodu. Działacze LGBT+ zarzucają fundacji finansującej furgonetki szerzenie homofobicznej mowy nienawiści. Same zaś samochody nazywają „pogromobusami”.

Manifestacja została zwołana następnego dnia po zatrzymaniach. Protestowano także przeciwko bru- talnemu zachowaniu policjantów i dyskryminacyjnej polityce obozu rządzącego, w którego retoryce i kampaniach „ideologia LGBT” stała się jednym z głównych zagrożeń.

Manifestacja miała jednak również szczególną atmosferę pozbawionej lęku celebracji tożsamości osób LGBT+, znaną z Parad Równości. Złożyły się na nią emocjonalne przemówienia, taneczna muzyka i żywiołowy publiczny taniec, koncert na żywo, oflagowanie socrealistycznych pomników, wreszcie wyraziste stylizacje modowe i makijaż obecnych. Rzucała się w oczy duża reprezentacja osób transseksualnych, zwykle słabiej widocznych w dyskusjach i wydarzeniach ruchu LGBT+. Obok tęczowej flagi widać było także ich symbol - flagę błękitno-różowo-białą. Zauważalny był wreszcie bardzo liczny udział młodzieży w wieku studenckim i licealnym.

Piotr Szenajch

\section{„Czy można przewidzieć przyszłość?" \\ Sztuka uliczna (street art) jako sztuka zaangażowana społecznie}

Rzeczywistość 2020 - zdjęcia wykonane w 2012 roku w Warszawie na ulicy Chmielnej.
Autor plakatów nieznany.

Elżbieta Prucnal-Tumasz 

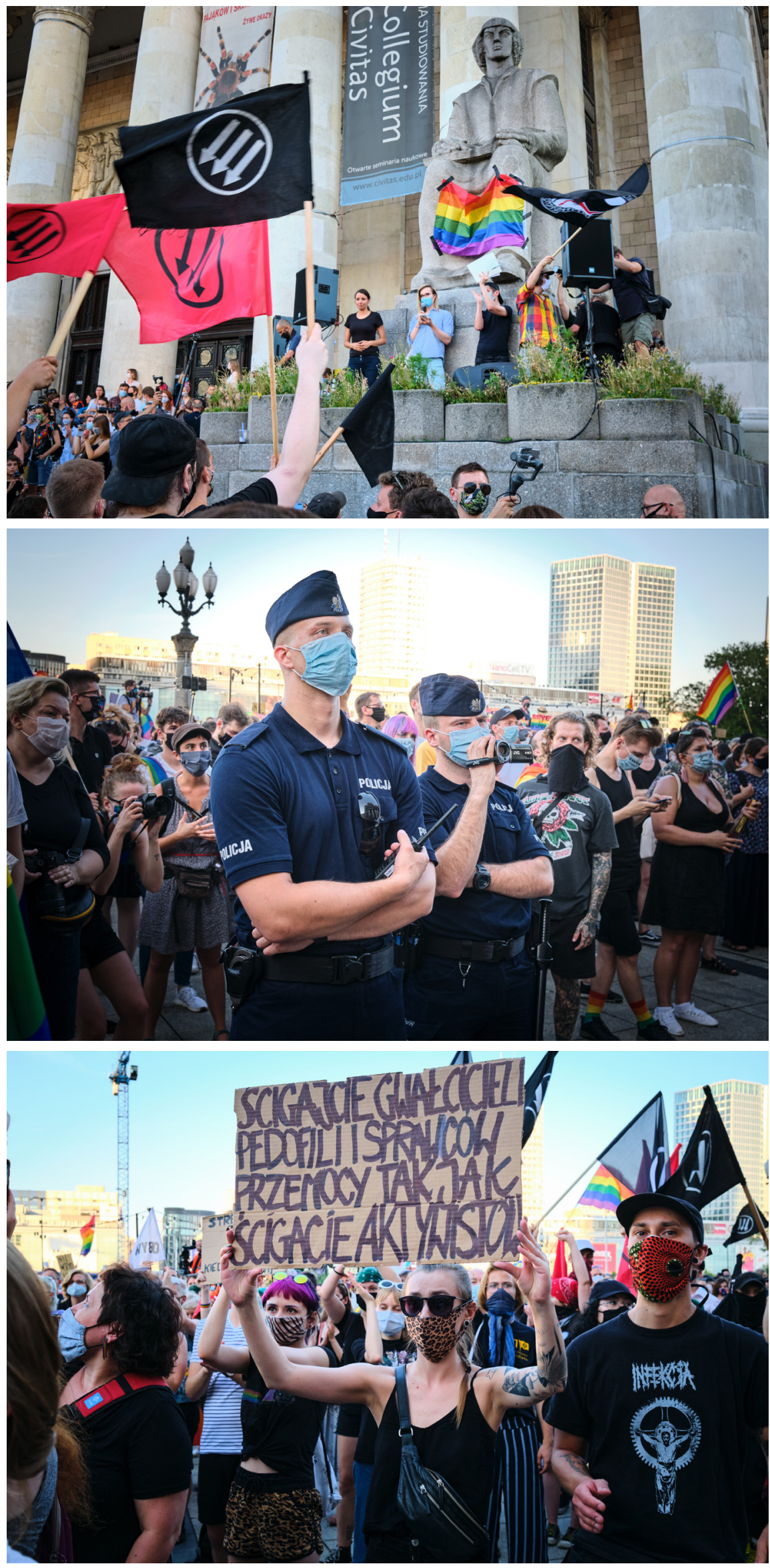

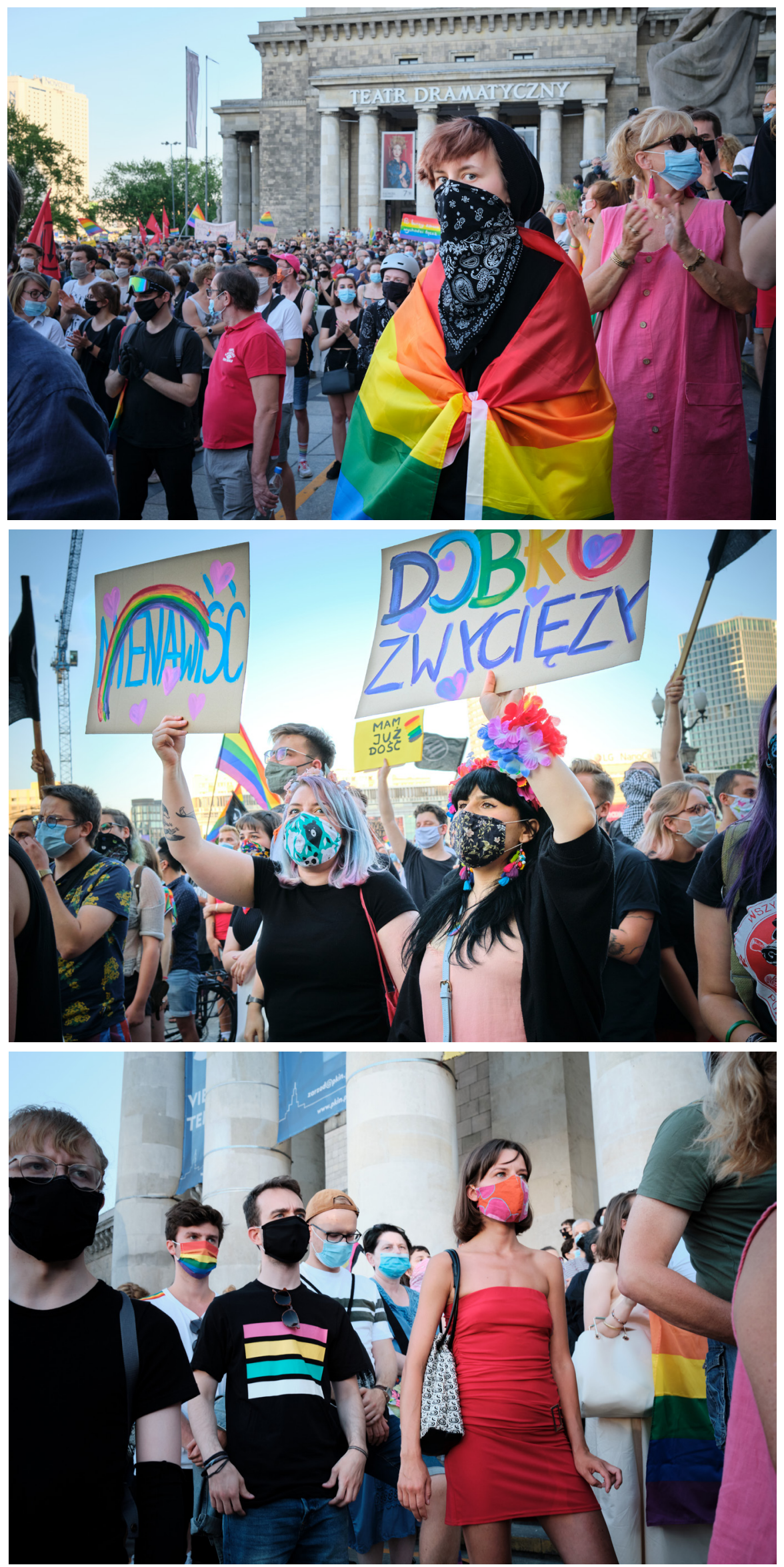

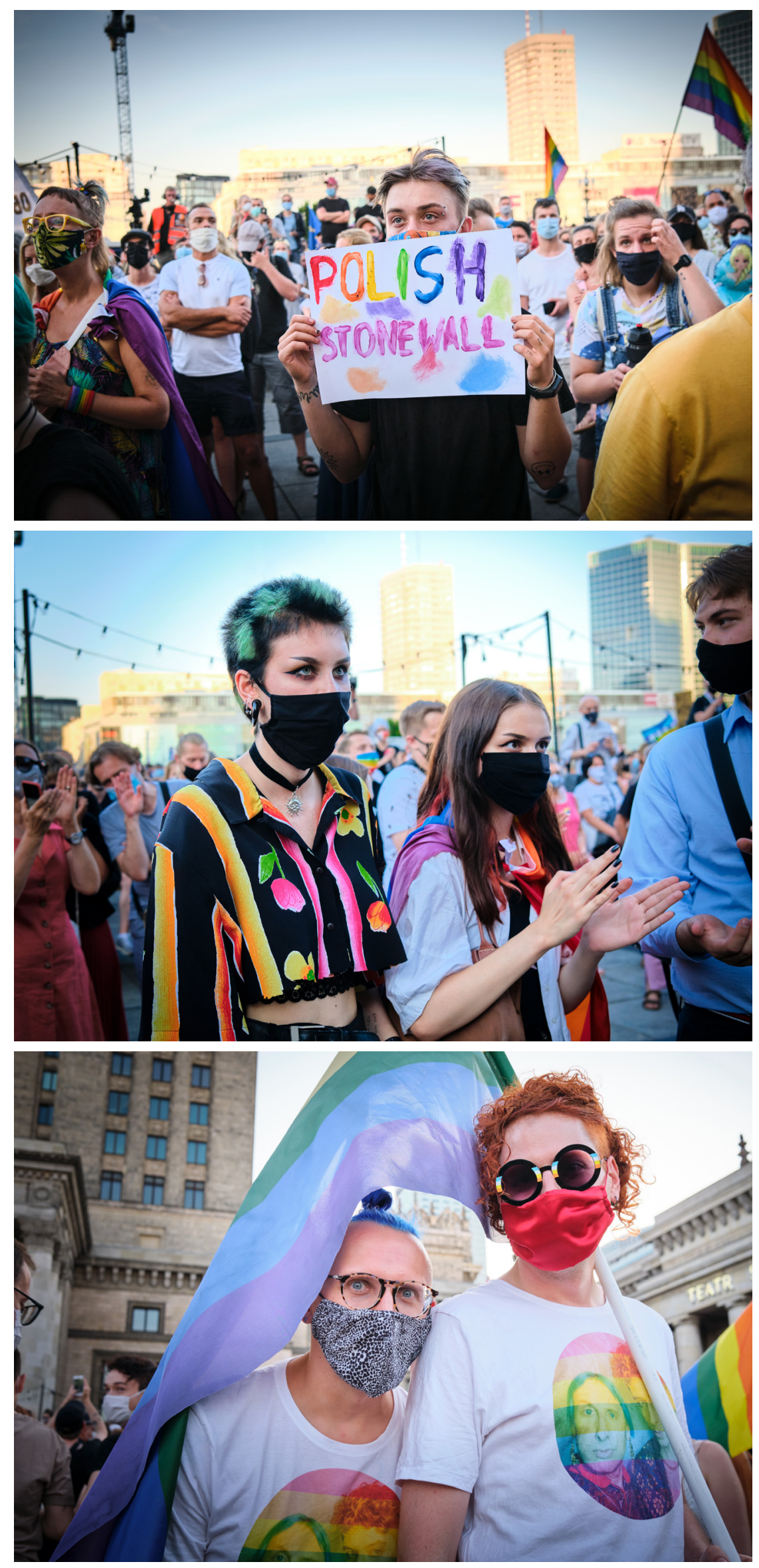

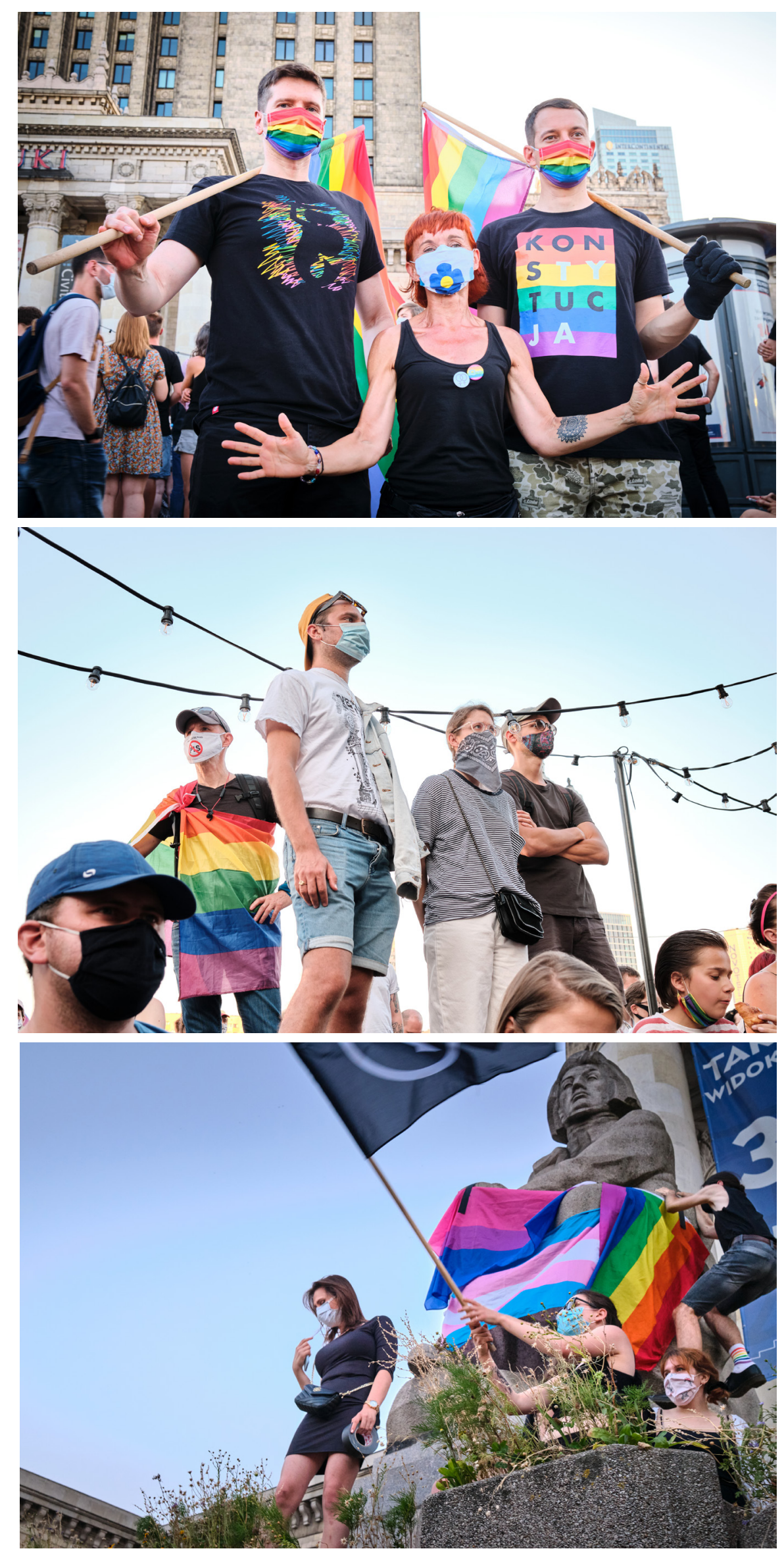

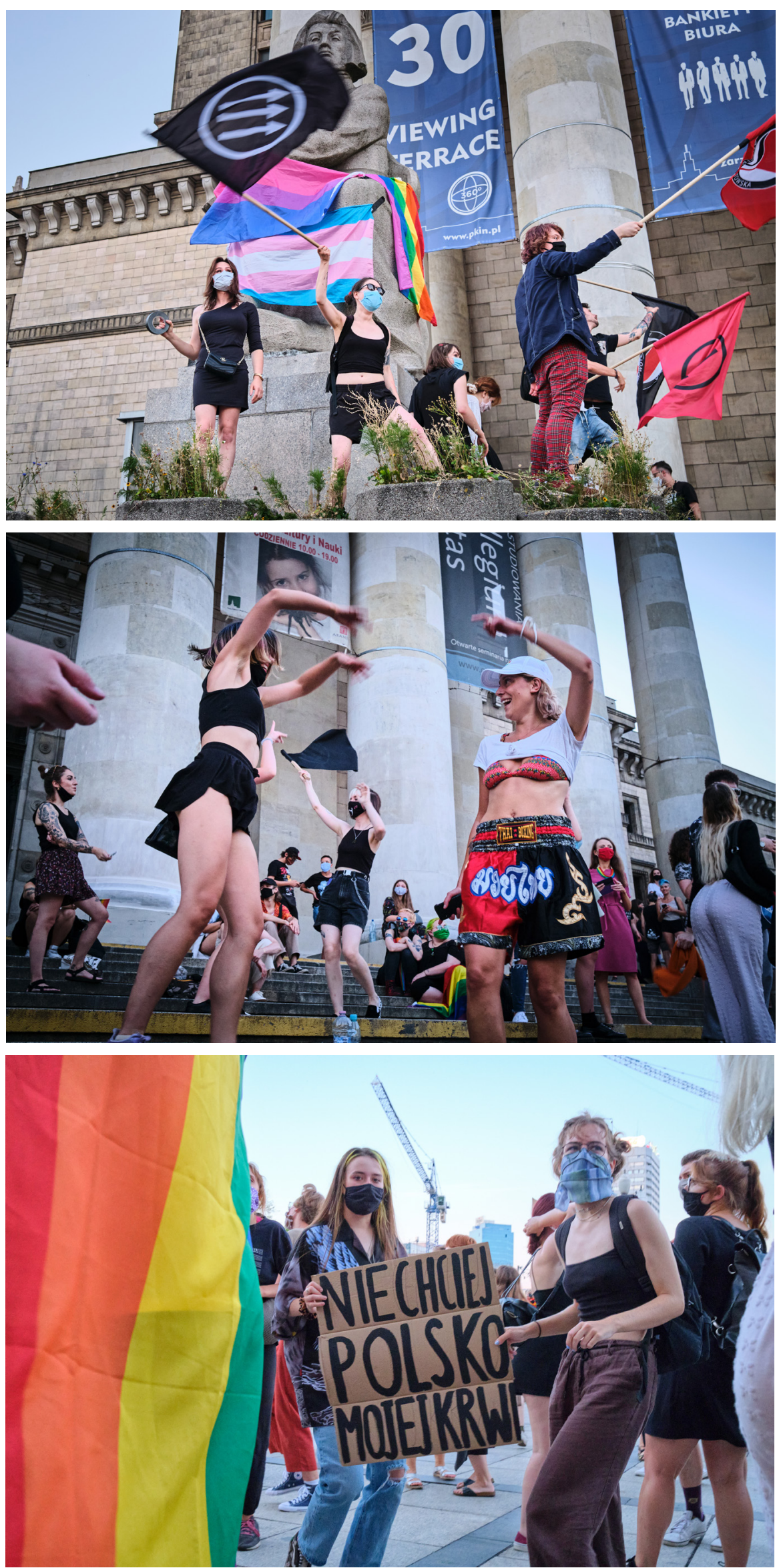

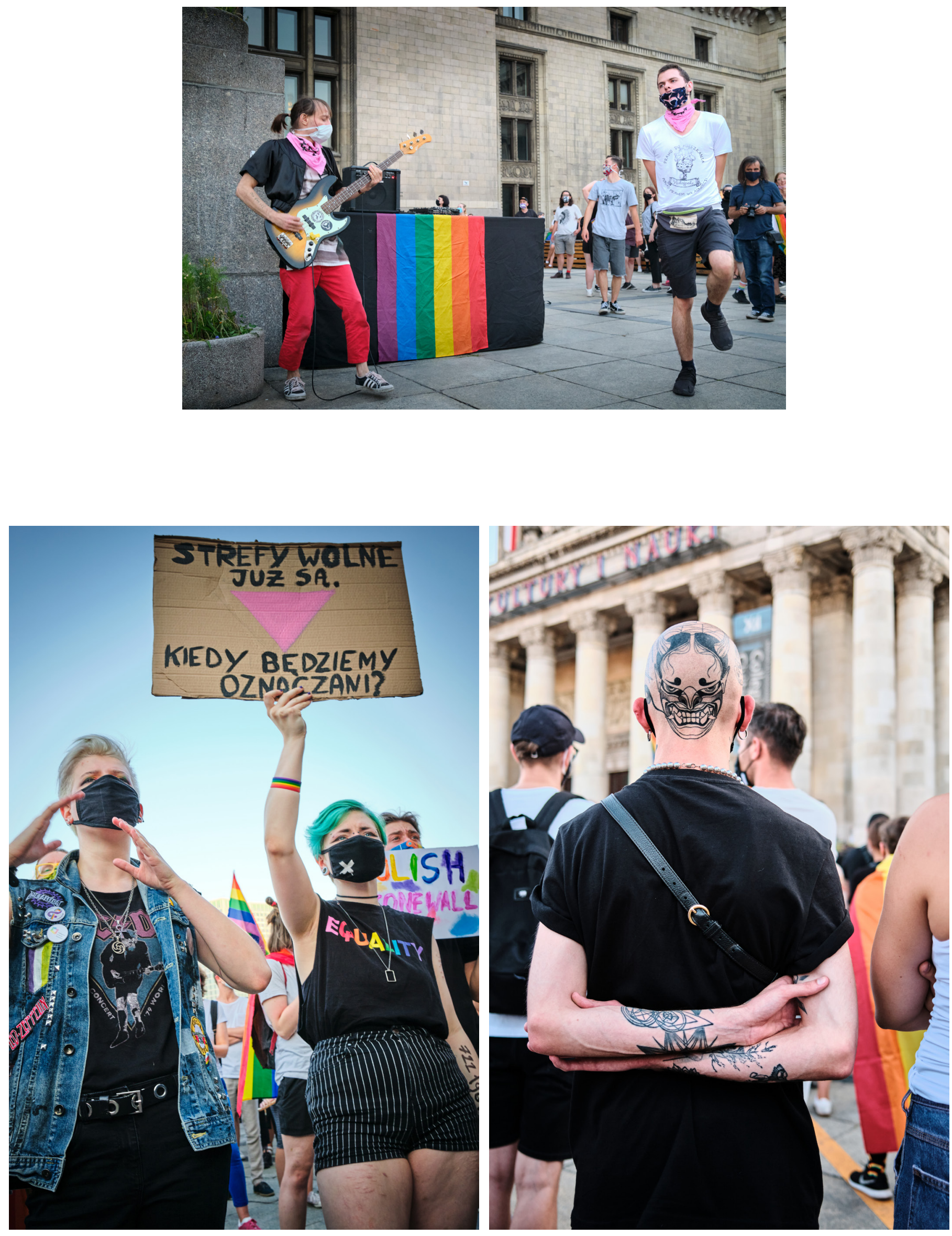

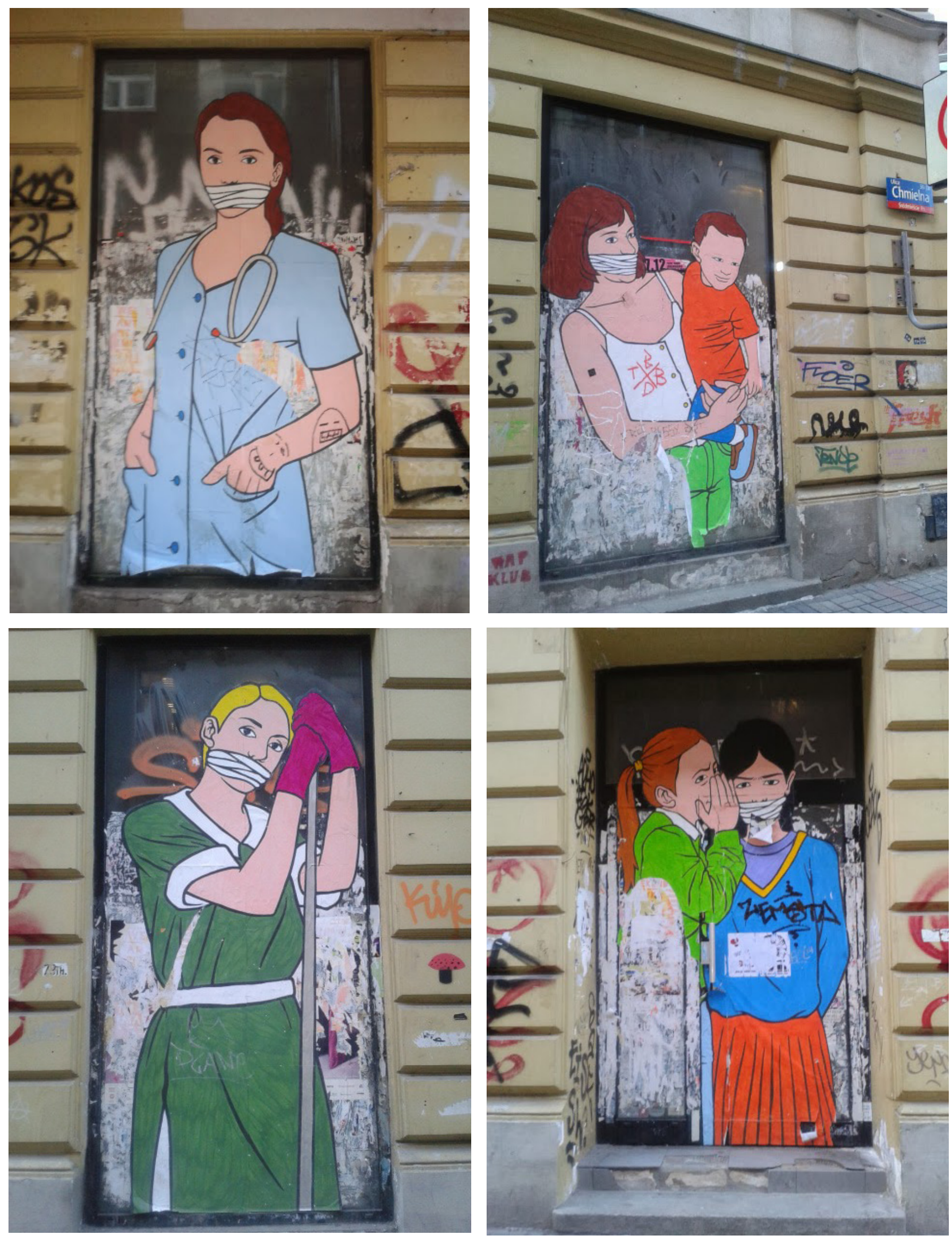

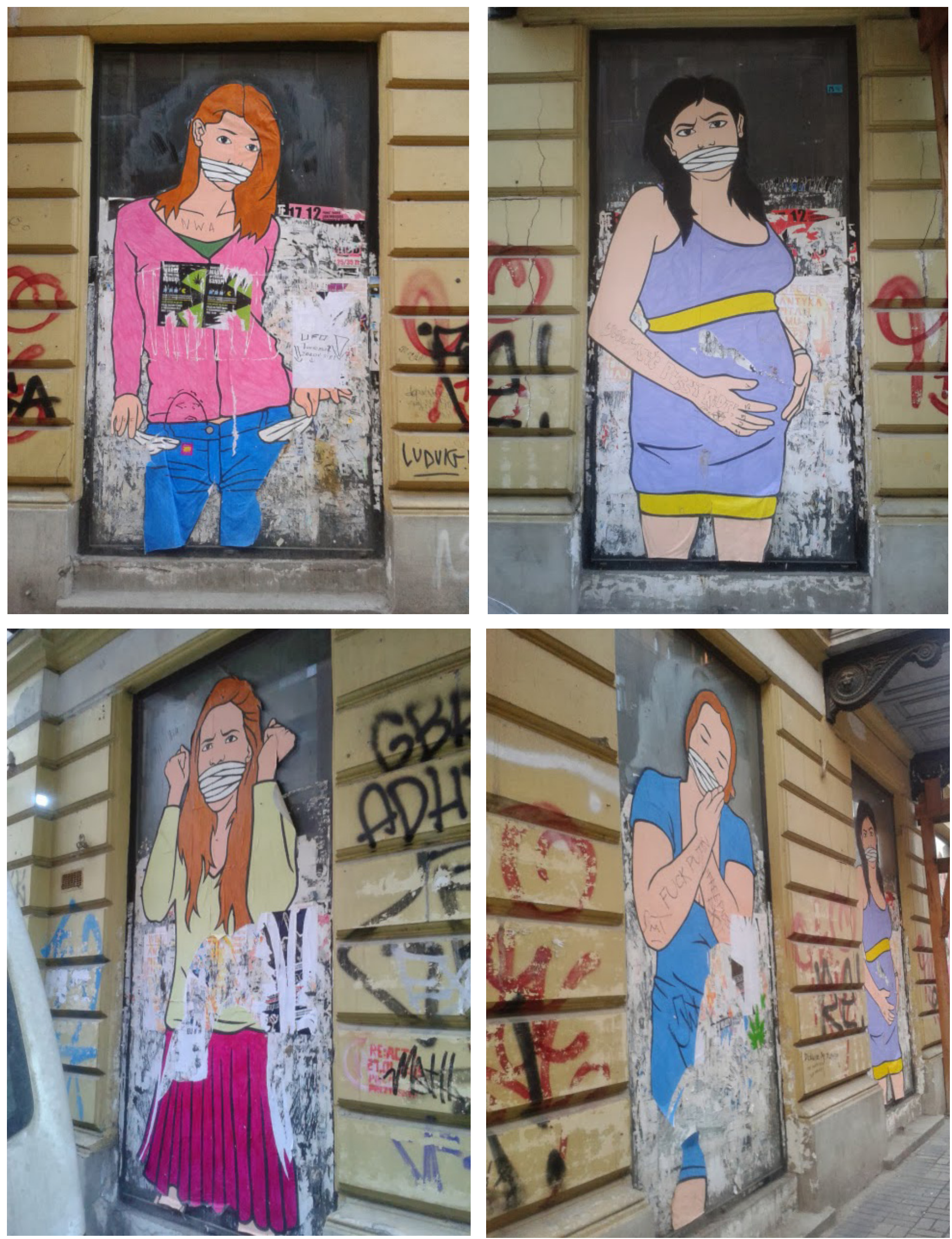